\title{
MicroCT survey of larval skeletal mineralization in the Cuban gar Atractosteus tristoechus (Actinopterygii; Lepisosteiformes)
}

\author{
Scherrer Raphaël ${ }^{1}$, Hurtado Andrés ${ }^{2}$, Garcia Machado Erik ${ }^{3}$, Debiais-Thibaud Mélanie ${ }^{1 *}$ \\ ${ }^{1}$ Institut des Sciences de l'Evolution de Montpellier, UMR5554, Université Montpellier, CNRS, IRD, EPHE, c.c.064, place Eugène Bataillon, \\ 34095 Montpellier Cedex 05, France \\ ${ }^{2}$ Centro Hidrobiológico, Parque Nacional Ciénaga de Zapata, Matanzas, Cuba \\ ${ }^{3}$ Centro de Investigaciones Marinas, Universidad de La Habana, Calle 16, No. 114 entre la 1ra y 3ra, Miramar, Playa, La Habana 11300, Cuba \\ ${ }^{*}$ Corresponding author: Melanie.Debiais-Thibaud@umontpellier.fr
}

\begin{abstract}
Using X-ray microtomography, we describe the ossification events during the larval development of a non-teleost actinopterygian species: the Cuban gar Atractosteus tristoechus from the order Lepisosteiformes. We provide a detailed developmental series for each anatomical structure, covering a large sequence of mineralization events going from an early stage (13 days post-hatching, $21 \mathrm{~mm}$ total length) to an almost fully ossified larval stage (118dph or $87 \mathrm{~mm}$ in standard length). With this work, we expect to bring new developmental data to be used in further comparative studies with other lineages of bony vertebrates. We also hope that the online publication of these twelve successive 3D reconstructions, fully flagged, will be an educational tool for all students in comparative anatomy.
\end{abstract}

Keywords: Actinopterygii, development, Lepisosteiformes, mineralization, skeleton

Submitted:2016-04-04, published online:2017-05-17. https://doi.org/10.18563/m3.3.3.e3

\section{INTRODUCTION}

Gars are non-teleost ray-finned fishes (Actinopterygii) belonging to the order Lepisosteiformes, whose only extant family is Lepisosteidae. The seven extant species of gars have been categorized in the genera Lepisosteus (4 species) and Atractosteus ( 3 species). They are large (less than 1 meter to more than 2 meters long) ambush predators inhabiting freshwaters of North and Central America, up to Cuba (Wiley, 1976; Nelson et al., 2016). Lepisosteiformes belong to Ginglymodi, a group of actinopterygians that had its maximum diversity during the Late Cretaceous (Wiley, 1976; Grande, 2010) and included one other extinct order, $\uparrow$ Semionotiformes, according to the most recent evidence by López-Arbarello (2012) who placed the earliest re-assigned fossil of Lepisosteiformes during the Early Jurassic (around 190-200 million years ago (Mya)).

Lepisosteiformes make up one of the few lineages of rayfinned fishes that are not teleosts, referred to by many as 'basal', 'lower' or 'primitive' actinopterygians (e.g. Lauder, 1980; Gardiner and Schaeffer, 1989; Gardiner et al., 1996, 2005). The other extant lineages of non-teleost actinopterygians are Amiiformes (or Halecomorphi; one species, Amia calva), Acipenseriformes (or Chondrostei; sturgeons and paddlefishes) and Polypteriformes (or Cladistia; bichirs). The monophyly of Holostei (sistergroup to Teleostei) made up by Lepisosteiformes and Amiiformes, is supported by most of the recent molecular and anatomical/paleontological datasets (Normark et al., 1991; Lecointre et al., 1994; Hurley et al., 2007; Grande, 2010; Near et al., 2012; Betancur-R et al.,
2013; Broughton et al., 2013; Friedman, 2015). Near et al. (2012) estimated the separation between gars and teleosts between 330 and 390 million years ago (Mya), somewhere from Late Devonian to Early Carboniferous. According to the same studies, Holostei and Teleostei make up the clade Neopterygii, sister group to Acipenseriformes with which they make up the clade Actinopteri. Finally, Polypteriformes diverged from Actinopteri at the crown age of extant Actinopterygii, which was estimated at 380-430 Mya (Near et al., 2012), roughly between the Late Silurian and the Early Devonian.

Because of their phylogenetic position, gars have been a key taxon to many morphological studies. Ancient literature is available on comparative anatomy of actinopterygians including gars: Gegenbauer (1887) and Sewertzoff (1895) described the occipital region of fishes and its development, Schreiner (1902) compared more specifically Lepisosteiformes and Amia, Luther (1913) described cranial musculature and nerves with comparison with lungfishes, and Schmalhausen (1913), Kryzanovsky (1927) and Jessen (1972) documented fins and their development. Lauder (1980) studied the biomechanics of feeding in Polypterus, Lepisosteus oculatus and Amia. Arratia and Schultze (1991) published an extensive study of the morphology and development of the palatoquadrate (the structure in the skull responsible for articulating the lower jaw to the cranium, and that can be a significant component of the upper jaw in non-teleost lineages) in actinopterygians and some sarcopterygians. More recently, Britz and Johnson (2010) documented the patterns of fusion of vertebrae to the occiput in actinopterygians, showing that gars have a specific pattern, where the two first vertebrae are fused to the occiput. 
Comparative studies involving gars have also helped to document evolutionary convergences, such as the independent acquisition of an elongated body shape in distantly related ambush predators such as pikes (Esox), needlefishes (Belone) and gars (Maxwell and Wilson, 2013). Another example is the ability to breathe atmospheric oxygen with their swimbladder, analogous to the air-breathing swimbladder of Amia and some basal Teleostei as well as the lungs of Polypteriformes, lungfishes and tetrapods (Perry et al., 2001). Gars are also a key taxon to understand the evolution of scales in vertebrates. They have a peculiar type of scales, the ganoid scales, that are a synapomorphy of actinopterygians but remain only in Polypteriformes and gars (Helfman et al., 2009). Comparative studies aimed at uncovering homology relationships between ganoid scales, placoid scales of sharks, elasmoid scales of teleosts and tooth-like structures in general (Sire et al., 1987, 2009, Sire, 1989, 1990; Huysseune and Sire, 1998; Vickaryous and Sire, 2009).

Skeletal anatomy and development of gars have been documented by a great number of previous studies. Veit (1907) described the development of the skull in L. osseus. Mayhew (1924) and Hammarberg (1937) described in details the skull of L. platostomus and its development. Jollie (1984) described the development of the skull and the pectoral fins in L. osseus, L. platostomus and A. spatula, and also the patterning of the lateral line sensory system in the head of L. osseus. Long and Ballard (2001) described the early external development of $L$. osseus from the zygote until the yolk disappearance. In 2006, Kammerer et al. studied the development and kinetics of the jaws related to feeding behavior in L. osseus and A. spatula, also looking at adults of other extant and extinct species of gars. In a recent work, Hilton et al. (2014) described the development of the lower jaw in L. osseus. The main reference work on the skeleton of gars and its development is, however, the published book by Grande (2010) who described fossil and extant species and reviewed former descriptions. With similar exhaustive studies on Amia (Grande and Bemis, 1998) and Chondrostei (Grande and Bemis, 1991), this survey provides a synthetic framework on the morphology of non-teleost actinopterygians.

A new concern has arisen on the utility of including more developmental data in comparative studies, because they add new characters and yield deeper analyses when combined with traditional morphological data (Rücklin et al., 2014; Hilton et al., 2015). To this aim, the usefulness of new non-invasive techniques such as Micro Computed Tomography ( $\mu \mathrm{CT})$ has been pinpointed by some authors for their potential to provide good quality developmental data (Metscher, 2009; Rücklin et al., 2014; Hilton et al., 2015), especially for skeletal structures. Konstantinidis et al. (2015) investigated the development of jaw musculature in L. osseus, capturing for the first time gar development with $\mu \mathrm{CT}$ technology. Besides, $\mu \mathrm{CT}$ has yielded skeletal developmental data for a variety of vertebrates: coelacanths (Schultze and Cloutier, 1991), snakes (Boughner et al., 2007; Palci et al., 2016), stingrays (Dean et al., 2009), frogs

$\begin{array}{cl}\text { Inventory number } & \text { Characteristics } \\ \text { At1 } & 13 \text { dph larva, 21 mm TL } \\ \text { At2 } & 16 \text { dph larva, 26mm SL } \\ \text { At3 } & 19 \text { dph larva, 27mm SL } \\ \text { At4 } & 22 \text { dph larva, 30mm SL } \\ \text { At5 } & 26 \text { dph larva, 32mm SL } \\ \text { At6 } & 31 \text { dph larva, 39mm SL } \\ \text { At7 } & 37 \text { dph larva, 43mm SL } \\ \text { At8 } & 52 \text { dph larva, 46mm SL } \\ \text { At9 } & 74 \text { dph larva, 61mm SL } \\ \text { At10 } & 89 \text { dph larva, 63mm SL } \\ \text { At11 } & 104 \text { dph larva, 70mm SL } \\ \text { At12 } & 118 \text { dph larva, 87mm SL }\end{array}$

Table 1. Inventory number, age and length characteristics for each specimen. TL: total length. SL: Serial length

(Slater et al., 2009), mice (Shen et al., 2013; Ho et al., 2015), crocodilians (Dufeau and Witmer, 2015), turtles (Rice et al., 2016) and catsharks (Enault et al., 2016). To the best of our knowledge, however, a description of the development of the whole skeleton in gars with precise timings of ossification is still lacking, and 3D surfaces of the whole ossified skeleton at different stages are not available although it would be a valuable source of additional characters in comparative studies but also in educational contexts.

With this aim in mind, we hereby provide a $\mu \mathrm{CT}$ developmental series of the mineralized skeleton in the Cuban gar, Atractosteus tristoechus, a species for which development has never been investigated (see Table 1). Our high resolution of larval stages allows us to give details on the ossification times of most of the structures present in an adult skeleton. Also, our hope is that our data will serve as a good support for further work focusing on more detailed aspects of gar anatomy and development, will motivate similar exploratory studies in other species, and that the published 3D reconstructions will be used in comparative anatomy classes.

\section{METHODS}

Individuals of Atractosteus tristoechus used for this study were raised in the Centre for reproduction of the indigenous ichthyofauna, National Park Zapata swamp, Cuba. Two females and four males were used for reproduction. The fertilized eggs were transferred to fifty-liter aquaria and larvae were fed ad libitum with live Moina sp. after hatching. During this period the animals were reared in natural conditions without control of environmental parameters. The temperature ranged from 24 to $31^{\circ} \mathrm{C}$ and the water was taken directly from the surrounding swamp.

Larvae were fixed in $70 \%$ ethanol, and then moved to a PBS solution before scanning. The scans were obtained on an X-ray microtomograph SkyScan 1076 at the University of Montpellier (SkyScan/Bruker microCT, Kontich, Belgium). The resolution was set to a voxel size of $18 \mu \mathrm{m}$. Images were processed with the software NRECON (SkyScan/Bruker microCT, Kontich, Belgium) and Fiji (Schindelin et al., 2012) 


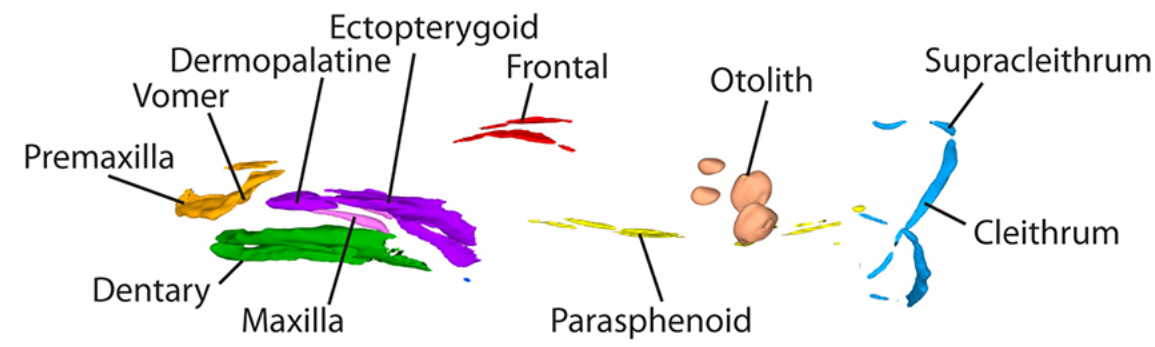

A

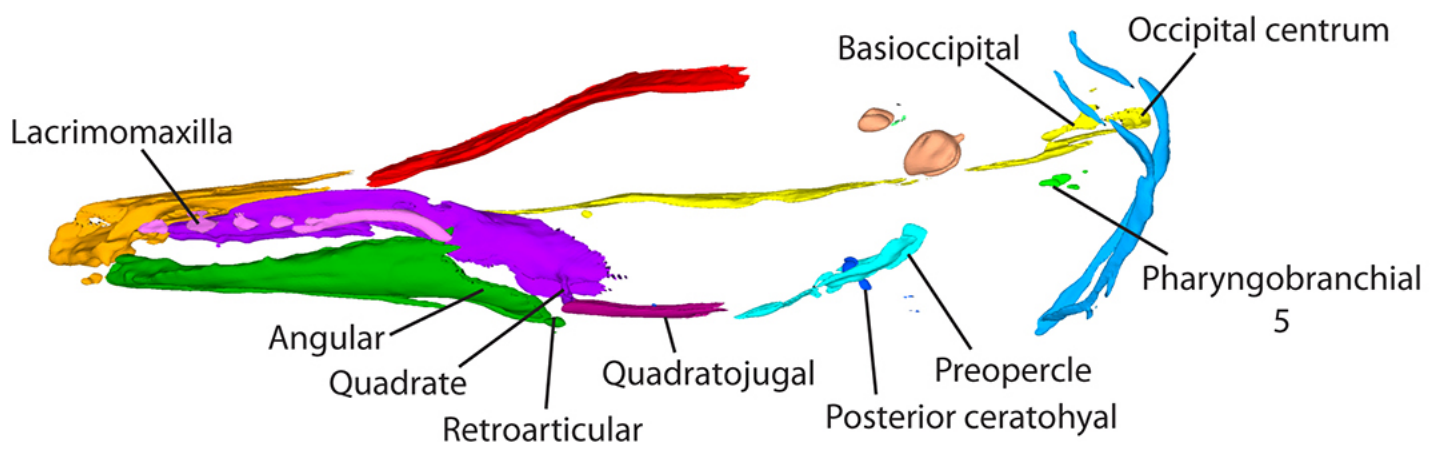

\section{B}

Retroarticular

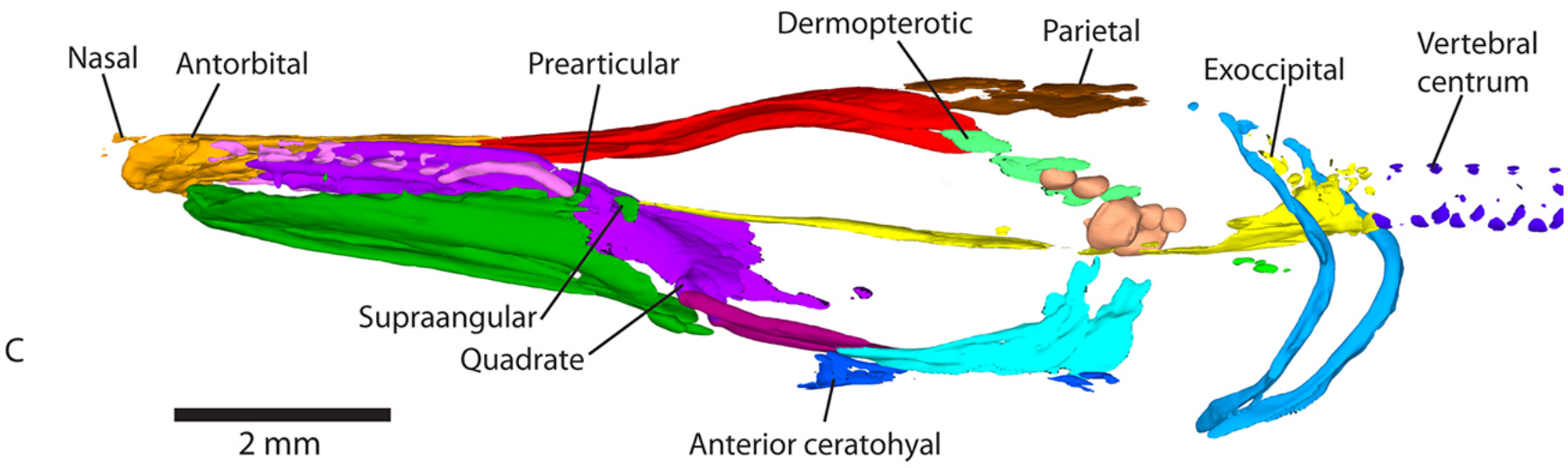

Figure 1. Lateral views of 3D models of the mineralized skull in Atractosteus tristoechus larvae: At1 13dph - 21mm TL (A), At3 19dph $27 \mathrm{~mm}$ SL (B) and At5 26dph - 32mm SL (C). The postcranial skeleton is not shown as it is not (A, B) or very poorly (C) ossified at this stage. For each stage, labels are given only for newly ossified structures. Tag color legend: please refer to the 3D models on the website. 
with the same settings for all the larvae. 'Iso-surface' 3D models, in PLY format, were reconstructed using AVIZO v6.3 (Visualization Sciences Group Inc., Burlington, MA, USA). For this step, X-ray density thresholds used to reconstruct calcified areas were calibrated based on Alizarin-red staining of the same larvae. Models were colored with the open-source software MeshLab v1.3.3 (Cignoni et al., 2008; http://meshlab.sourceforge.net/). ISE-MeshTools (Lebrun, 2014) was used to label structures, to tag anatomical assemblages based on their color and to extract position matrices. For each stage, one 3D model is available in a PLY file together with one FLG file containing "flags" (labels) and one POS file containing a position matrix. One TAG file applying to all the reconstructions is provided with the At1 model.

In total, 12 reconstructions are provided, each one corresponding to a single stage from 13 days post-hatching (dph) and $15 \mathrm{~mm}$ in total length (TL) to $118 \mathrm{dph}$ and $87 \mathrm{~mm}$ in standard length (SL) (after Grande, 2010; see Table 1 for the specimen list). One specimen was scanned per stage. Color tags on the figures correspond to anatomical assemblages each bone belongs to (see tags provided with model At1). On models At9, At10 and At11, only some structures that showed changes over that time period have been tagged. Terminology for anatomical structures follows the reference work of Grande (2010) based on larval and adult gars.

\section{RESULTS}

In the following descriptions, structures which are symmetrically paired (with a left and a right copy e.g. the frontal bones) are referred to by using the singular. Plural designates structures that occur in more than one copy on one side (e.g. lacrimomaxillae).

\section{Endoskeleton - the skull}

The actinopterygian skull is a complex mosaic with more bones than the tetrapod skull (Gregory, 1959). In Atractosteus tristoechus the skull is the first region of the skeleton to ossify (Fig. 1). Globally, it mineralizes from anterior to posterior (Fig. 2), starting around 13 days post-hatching (dph) or $21 \mathrm{~mm}$ in total length (TL), according to alizarin red staining (data not shown). Most of the adult structures and connections between bones are present at $118 \mathrm{dph}$ or $87 \mathrm{~mm}$ in standard length (SL), which was our oldest specimen (Fig. 3E and Fig. 4).

We first describe the jaw region: the snout, the lacrimomaxillary series (a lateral series of tooth-bearing bones along the upper jaw), the palatopterygoquadrate (the complex of bones constituting the upper jaw and its articulation to the lower jaw and braincase), and the lower jaw. In a second part, we describe the ossification timing for some ornamented superficial bones arising from the dermatocranium: the temporal region, the opercular apparatus, the circumorbital series, and the dermal roof of the skull. Thirdly are presented internal structures forming the braincase such as the otic complex and the parasphenoid; and splanchnocranial structures (i.e. arising from the pharyngeal arches) such as the hyoid complex and the gill arches. Finally, we describe the occipital region and the most anterior part of the vertebral column.

\section{Snout.}

The premaxilla and vomer are ossified and connected at 13dph $-21 \mathrm{~mm}$ TL (Fig. 1A and model At1). The nasal and antorbital ossify, and the premaxilla connects to the dermopalatine at 26dph $-32 \mathrm{~mm}$ SL (Fig. 1C and model At5). Ossification of the rostral bone is detected, and the antorbital connects to the premaxilla, which connects to the nasal and frontal, at 31dph - 39mm SL (model At6). The vomer connects to the anterior tip of the parasphenoid at $37 \mathrm{dph}-43 \mathrm{~mm}$ SL (model At7).

\section{Lacrimomaxillary series.}

The posterior-most bone of the lacrimomaxillary series, i.e. the maxilla, is calcified at $13 \mathrm{dph}-21 \mathrm{~mm}$ TL (Fig. 1A). The four left and five right anterior-most lacrimomaxillae are first detected at 19dph $-27 \mathrm{~mm} \mathrm{SL}$ (Fig. 1B and model At3 ). The maxilla connects to the ectopterygoid at 26dph $-32 \mathrm{~mm} \mathrm{SL}$ (see model At5). The anterior lacrimomaxillae connect to the dermopalatine-ectopterygoid at 31dph $-39 \mathrm{~mm}$ SL, while the posterior ones connect to the maxilla, which connects to the anterior lacrimal (model At6).

\section{Palatopterygoquadrate.}

Both the dermopalatine and ectopterygoid are mineralized at 13dph $-21 \mathrm{~mm}$ TL (Fig. 1A and model At1) and connect together at 16dph - 26mm SL (see model At2). Ossification of the quadrate is detected at $19 \mathrm{dph}-27 \mathrm{~mm}$ SL (Fig. 1C and model At3 ) and is fully connected to the ectopterygoid at $22 \mathrm{dph}-30 \mathrm{~mm}$ SL (model At4). The metapterygoid calcifies at $37 \mathrm{dph}-43 \mathrm{~mm}$ SL (Fig. 2C and model At7). The endopterygoid seems to ossify between $37 \mathrm{dph}-43 \mathrm{~mm}$ SL and 52dph - 46mm SL (model At8). The metapterygoid and the endopterygoid connect to the ectopterygoid at 89dph $63 \mathrm{~mm}$ SL (see model At10).

\section{Lower jaw.}

Ossification of the dentary is detected surrounding the Meckel's cartilage at $13 \mathrm{dph}-21 \mathrm{~mm}$ TL (Fig. 1A and model At1). Ossification of the retroarticular and the angular is detected at $19 \mathrm{dph}-27 \mathrm{~mm} \mathrm{SL}$, the latter appearing in continuity with the dentary (Fig. 1B, and see model At3 for better details). The prearticular and the supraangular ossify at $26 \mathrm{dph}-32 \mathrm{~mm} \mathrm{SL}$ (although light ossification of the right supraangular is already visible at $19 \mathrm{dph}-27 \mathrm{~mm}$ SL (At3) but almost not in the $22 \mathrm{dph}$ - 30mm SL specimen (At4)), with the prearticular already connected to the dentary (Fig. 1C and model At5). The articular mineralizes and the angular connects to the retroarticular at $31 \mathrm{dph}-39 \mathrm{~mm}$ SL (Fig. 2B, model At6). The dentary connects to the supraangular while the articular connects to the prearticular at $37 \mathrm{dph}-43 \mathrm{~mm}$ SL (see model At7).

\section{Cheek region.}

At $16 \mathrm{dph}-26 \mathrm{~mm}$ SL, the quadratojugal starts to ossify and then connects to the preopercle and the quadrate at $22 \mathrm{dph}$ 

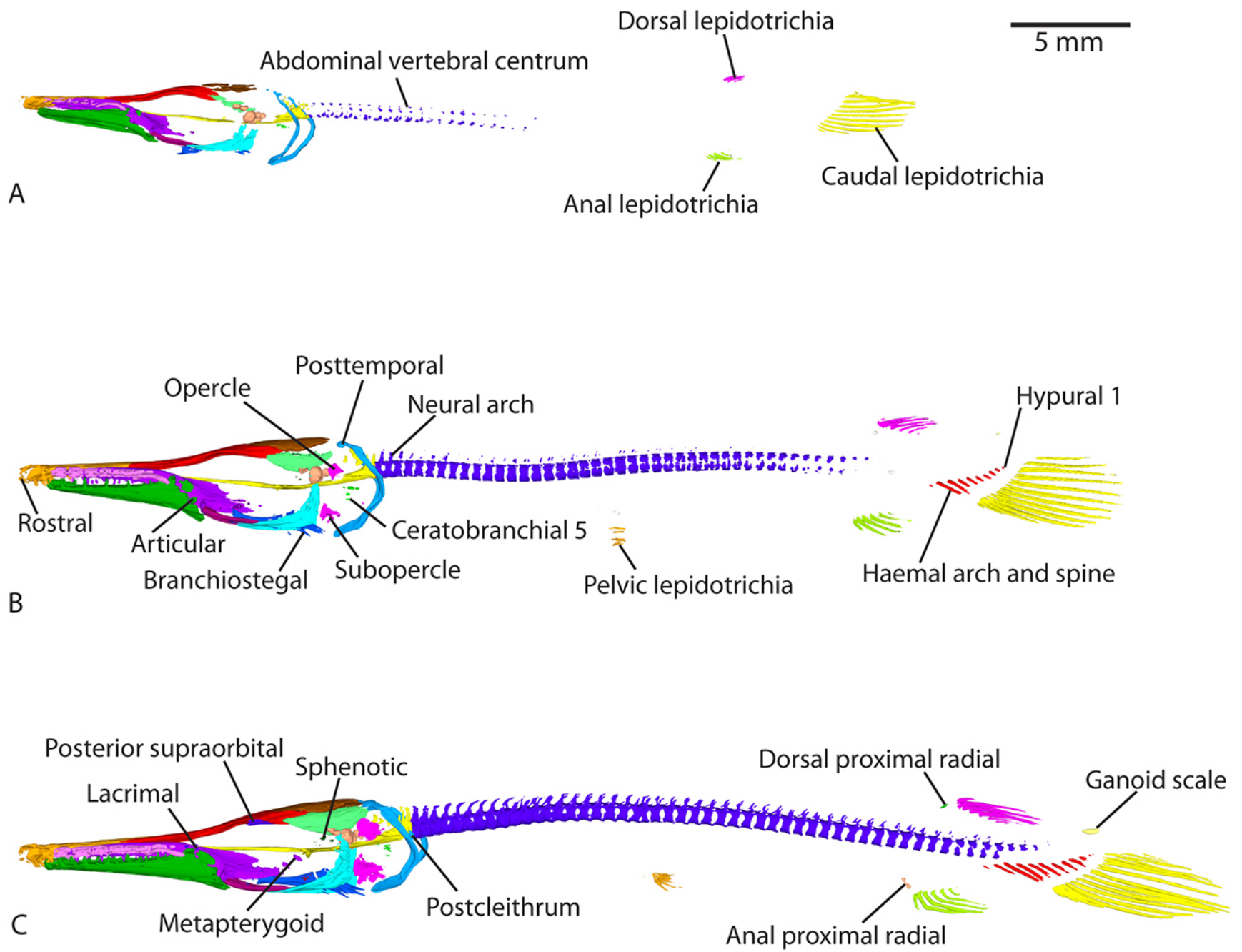

Figure 2. Lateral views of 3D models of the mineralized skeleton in Atractosteus tristoechus larvae: At5 26dph - 32mm SL (A), At6 31dph -39mm SL (B) and At7 37dph - 43mm SL (C). For each stage, labels refer only to newly ossified structures. 
- 30mm SL (see model At4). Between 37dph - 43mm SL and $52 \mathrm{dph}-46 \mathrm{~mm}$ SL the symplectic and hyomandibula bones appear, the latter being connected to the preopercle (see model At8). The symplectic connects to the preopercle and the quadratojugal connects to the most ventral postinfraorbital at 118dph - 87mm SL (model At12, Fig. 4).

\section{Opercular apparatus.}

The preopercle starts to ossify at $16 \mathrm{dph}-26 \mathrm{~mm}$ SL (see model At2). Ossification of the opercle and subopercle is detected at 31dph $-39 \mathrm{~mm}$ SL (Fig. 2B and model At6). Contact between the subopercle and preopercle is observed at 104dph - 70mm SL (model At11), while connection between the opercle and subopercle happens at $118 \mathrm{dph}-87 \mathrm{~mm}$ SL (model At12, Fig. 4).

\section{Circumorbital series.}

The anterior-most lacrimals, which are fragmentary in gars (Grande, 2010) are calcified at 31dph - 39mm SL (although one right lacrimal is barely visible at $26 \mathrm{dph}-32 \mathrm{~mm}$ SL), connected to the maxilla (see model At6). The posterior supraorbital is detected at $37 \mathrm{dph}-43 \mathrm{~mm}$ SL (Fig. 2C and model At7). Between $37 \mathrm{dph}-43 \mathrm{~mm}$ SL and 52dph $-46 \mathrm{~mm}$ SL, ossification of the anterior supraorbital is detected and the posterior supraorbital connects to the frontal (Fig. 3, see model At8). At 74dph-61mm SL (At9), the subinfraorbitals and the right dermosphenotic are first detected, the latter being connected to the posterior supraorbital (Fig. 3B, model At9). At the same stage, anterior and posterior supraorbitals connect together, and the anterior supraorbital connects to some posterior lacrimals while the posterior supraorbital connects to the frontal (on the left, then on both sides at $89 \mathrm{dph}-$ $63 \mathrm{~mm} \mathrm{SL}$ ). In the $89 \mathrm{dph}-63 \mathrm{~mm}$ SL larva, both left and right dermosphenotics are visible and connected to the posterior supraorbital, which connects to the dermopterotic (observed on the left side only, Fig. 3C, model At10; then on the right side at 104dph $-70 \mathrm{~mm}$ SL (At11)). The postinfraorbitals also mineralize at $89 \mathrm{dph}-63 \mathrm{~mm}$ SL (Fig. 3C, model At10) and then the most ventral postinfraorbital is connected to the quadratojugal at $118 \mathrm{dph}-87 \mathrm{~mm}$ SL while another comes into contact with the dermosphenotic (model At12, see left side of the specimen). The series of small suborbital bones supposed to cover the cheek (Grande, 2010) is still not visible at $118 \mathrm{dph}-87 \mathrm{~mm} \mathrm{SL}$ (At12).

\section{Dermal roof.}

The frontal is already calcified at $13 \mathrm{dph}-21 \mathrm{~mm}$ TL (Fig. $1 \mathrm{~A}$, model At1) while the parietal starts mineralizing at $22 \mathrm{dph}$ - 30mm SL (model At4), and the dermopterotic at 26dph $32 \mathrm{~mm}$ SL (Fig. 1C and model At5). The posttemporal calcifies and grows in contact with the supracleithrum at $31 \mathrm{dph}$ - 39mm SL while the frontal bone connects to the parietal, the dermopterotic and the premaxilla (model At6). At 37dph $-43 \mathrm{~mm}$ SL, ossification of the epioccipital is detected, connected anteriorly to the parietal and the dermopterotic, and posteriorly to the posttemporal (model At7). The parietal and the dermopterotic come into contact between $37 \mathrm{dph}-43 \mathrm{~mm}$ SL and 52dph $-46 \mathrm{~mm}$ SL (model At8). The lateral and the medial extrascapulars arise at $74 \mathrm{dph}-61 \mathrm{~mm}$ SL, the latter connected to the parietal and to the epioccipital (Fig. 3B, model At9). Another pair of ossified extrascapulars appears between the medial and the lateral one at $104 \mathrm{dph}-70 \mathrm{~mm}$ SL, in contact with the dermopterotic and the posttemporal, but also with the right parietal and the medial extrascapular (model At11). At the same time, the left medial extrascapular connects to the posttemporal and the right lateral extrascapular connects to the dermopterotic. At 118dph-87mm SL (At12), the intermediate pair of extrascapulars is fully connected to the lateral pair.

\section{Otic complex.}

The two anterior-most pairs of otoliths (from anterior to posterior: the lapilli and sagittae (Long and Snow, 2016)) are already well mineralized at $13 \mathrm{dph}-21 \mathrm{~mm}$ TL (Fig. 1A and model At1) while the posterior-most pair (the asterisci) starts to be visible in contact with the posterior zone of the sagittae at $22 \mathrm{dph}-30 \mathrm{~mm}$ SL (see model At4). The sphenotic starts to ossify at $37 \mathrm{dph}-43 \mathrm{~mm}$ SL (Fig. 2C and model At7) and the prootic can be detected between $37 \mathrm{dph}-43 \mathrm{~mm}$ SL and 52dph -46mm SL (models At7 and At8). From 37dph - 43mm SL to $118 \mathrm{dph}-87 \mathrm{~mm}$ SL, the sagittae and asterisci do not always appear in contact, and sometimes they do so only on one side.

\section{Hyoid complex.}

The posterior part of the ceratohyal starts to ossify at 19dph $-27 \mathrm{~mm}$ SL (Fig. 1B and model At3) while the anterior ceratohyal is detected at $22 \mathrm{dph}-30 \mathrm{~mm}$ SL (model At4). At this time, the branchiostegal rays become visible (although very small ossification patches are detected on the first pair at $19 \mathrm{dph}-27 \mathrm{~mm}$ SL). Ossification of the hypohyal starts between $37 \mathrm{dph}-43 \mathrm{~mm}$ SL and 52dph - 46mm SL (model At7 and At8).

\section{Gill arches.}

In adults of Atractosteus, the ventral arches are made of two medial and unpaired basibranchials, four pairs of hypobranchials and five pairs of ceratobranchials; while the dorsal arches are made of three pairs of infrapharyngobranchials and four pairs of epibranchials (Grande, 2010). What seems to be one of the numerous bones constituting the upper pharyngeal tooth plate (a tooth bearing plate attached to the ventral face of the third infrapharyngobranchial (Grande, 2010)) calcifies at $19 \mathrm{dph}-27 \mathrm{~mm}$ SL (Fig. 1B and model At3). It might be the third infrapharyngobranchial itself, but we cannot determine it solely with our reconstructions. The fifth pair of ceratobranchials arises at $31 \mathrm{dph}-39 \mathrm{~mm}$ SL (Fig. 2B and model At6). The first and second, anterior-most pairs of ceratobranchials are detected between $37 \mathrm{dph}-43 \mathrm{~mm}$ SL and 52dph-46mm SL (models At7 and At8). The third and fourth pairs of ceratobranchials start mineralizing at $89 \mathrm{dph}-63 \mathrm{~mm}$ SL, as well as the first and second pairs of hypobranchials (model At10). The third pair of hypobranchials is detected at 

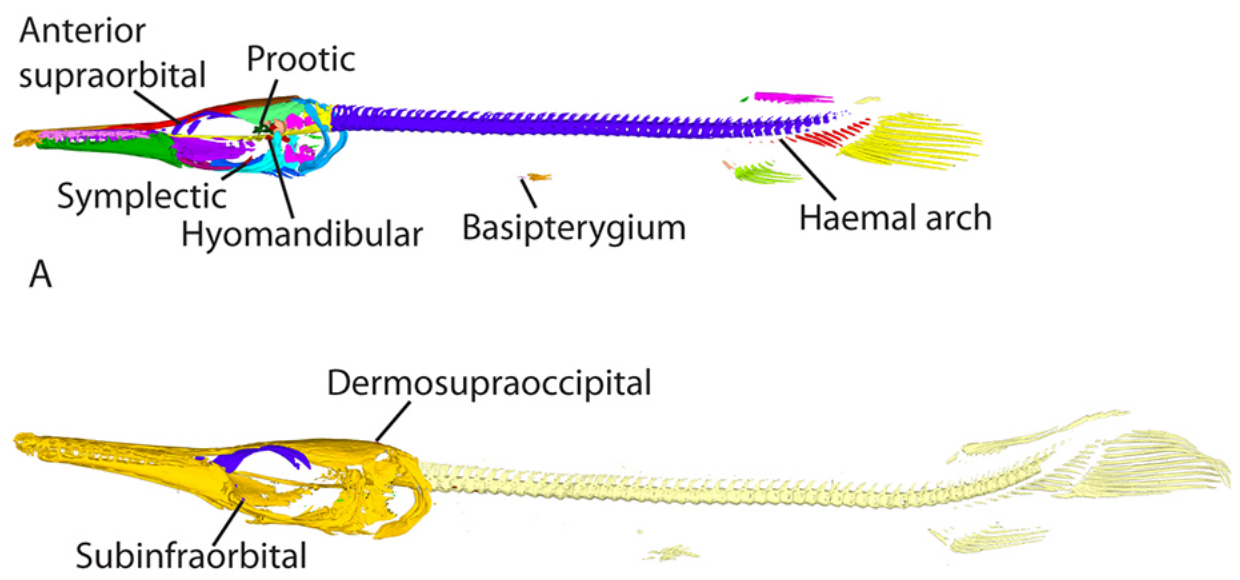

\section{B}

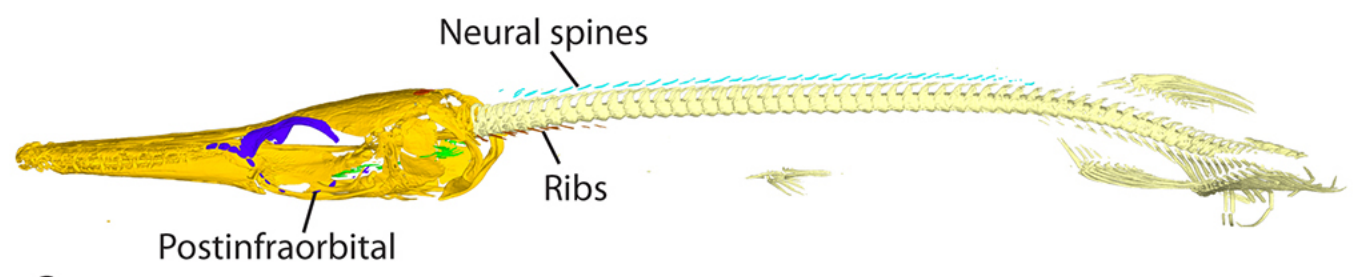

C

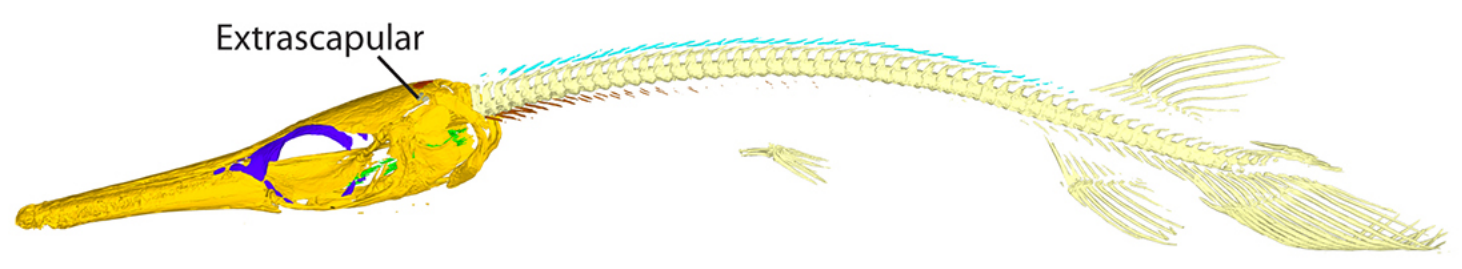

D

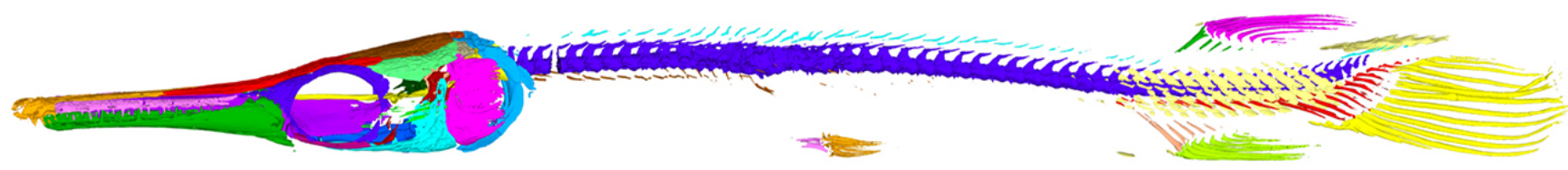

E

Figure 3. Lateral views of 3D models of the mineralized skeleton in Atractosteus tristoechus larvae: At8 52dph - 46mm SL (A), At9 74dph -61mm SL (B), At10 89dph - 63mm SL (C), At11 104dph - 70mm SL (D) and At12 118dph - 87mm SL (E). B-D: light-yellow refers to the postcranial skeleton while dark-yellow refers to the skull. For each stage, labels refer only to newly ossified structures. 
104dph - 70mm SL (model At11). Finally, the fourth pair of hypobranchials starts to ossify at $118 \mathrm{dph}-87 \mathrm{~mm}$ SL (model At12).

\section{Parasphenoid.}

The parasphenoid is a long bone at the ventral surface of the skull, oriented along the antero-posterior axis. To better locate the elements, we refer to the following regions from the anterior-most to the posterior-most location: snout region; orbital region; otic region and occipital region. Figures enclosed in the manuscript do not visibly display the growth of these structures; better observation is available with the 3D models.

The orbito-otic region of the parasphenoid is already detected at $13 \mathrm{dph}-21 \mathrm{~mm}$ TL (Fig. $1 \mathrm{~A}$ and model At1). The occipital region mineralizes at $19 \mathrm{dph}-27 \mathrm{~mm}$ SL, separated from the anterior part (Fig. 1B and model At3). The orbital region expands forwards to form the snout region, and the otic and occipital regions fuse at $31 \mathrm{dph}-39 \mathrm{~mm}$ SL (model At6).

\section{Occiput.}

The basioccipital ossifies at $19 \mathrm{dph}-27 \mathrm{~mm}$ SL, in contact with the occipital region of the parasphenoid (Fig. 1B, model At3). The anterior-most vertebral centrum fuses with the basioccipital-parasphenoid complex at 22dph - 30mm SL (only the ventral part of the centrum is ossified). At this stage, the second centrum is ossified ventrally but still independent from the occiput. The exoccipital is first detected at $26 \mathrm{dph}-32 \mathrm{~mm} \mathrm{SL}$, while the second centrum fuses to the first one and the first arterial foramens become visible in the occiput (Fig. 1C, model At5). At the same time, the first pair of neural arches ossifies, detached from the centrum. At $31 \mathrm{dph}-39 \mathrm{~mm}$ SL, the two occipital vertebrae are peripherally ossified, with their neural arches attached and their centra fused together and to the occiput. The exoccipital comes into contact with the anterior-most pair of neural arches between 37dph - 43mm SL and 52dph - 46mm SL (models At7 and At8). Finally, at $118 \mathrm{dph}-87 \mathrm{~mm}$ SL, the exoccipital connects to the epioccipital (model At12).

\section{Endoskeleton - the vertebral axis}

Here we refer to the different regions of the column as follows: (i) the occipital region made of the first two vertebrae fused with the occiput; (ii) the abdominal region (sensu Grande, 2010) is the subsequent large region covering almost all the body and ending at the deep insertion of the radials of the dorsal and anal fins; (iii) the caudal region is the most posterior part of the body.

\section{Centra.}

The two first centra ossify at $22 \mathrm{dph}-30 \mathrm{~mm}$ SL and then fuse to the occiput as described in the previous section. Calcification starts in the anterior part of the abdominal region at $22 \mathrm{dph}-30 \mathrm{~mm}$ SL (although the very first few centra of this region are not detected before $26 \mathrm{dph}-32 \mathrm{~mm}$ SL) and spreads backwards to reach the caudal region at $37 \mathrm{dph}-43 \mathrm{~mm} \mathrm{SL}$ (models At4 and At7). Mineralization of a centrum starts with two focal spots; a ventral one and a dorsal one. Both spread peripherally to the putative notochord to meet halfway and form the whole centrum. The parapophyses (lateral processes of the centra that bear the ribs) are detected in the anterior abdominal centra at $37 \mathrm{dph}-43 \mathrm{~mm}$ SL (At7) and their ossification spreads backwards, being visible up until the tail at $118 \mathrm{dph}-87 \mathrm{~mm}$ SL (At12). The two posterior-most vertebrae in the tail do not display ossified centra in the $118 \mathrm{dph}-87 \mathrm{~mm}$ SL specimen (At12).

\section{Neural arches and spines.}

Ossification of the neural arches starts with the occipital vertebrae at $26 \mathrm{dph}-32 \mathrm{~mm}$ SL (model At5, as described in the Occiput section) and spreads posteriorly, same as the centra but with a delay. Neural arches are detected in the abdominal region at $31 \mathrm{dph}-39 \mathrm{~mm}$ SL (model At6) and in the caudal region at $37 \mathrm{dph}-43 \mathrm{~mm}$ SL (model $\mathrm{At} 7$ ), while those in the abdominal region fuse with their centra. At this stage, the first neural spines (which are paired in gars; Grande, 2010) become distinguishable from their neural arches (which they are in continuity with) in the anterior part of the abdominal region (Fig. 2C and model At7). Neural arches attach to their centra in the caudal region between $37 \mathrm{dph}-43 \mathrm{~mm}$ SL (At7) and 52dph -46mm SL (Fig. 3A and model At8). Neural spines reach the caudal region around $89 \mathrm{dph}-63 \mathrm{~mm}$ SL (At10, neural spines and arches reach the most posterior vertebrae, unlike vertebral centra).

\section{Supraneurals.}

Supraneurals are small unpaired elements born by the neural spines. They are detected at $89 \mathrm{dph}-63 \mathrm{~mm}$ SL in the abdominal region (Fig. 3C and model At10) and their ossification spreads posteriorly to reach the anterior of the caudal region at 104dph - 70mm SL (At11). They do not grow posteriorly to the insertion of the dorsal fin.

\section{Epurals.}

Epurals are also born dorsally by the neural spines, but are present at the very tip of the tail only. They ossify at 89dph$63 \mathrm{~mm}$ SL (model At10).

\section{Ribs.}

Ribs are first detected at $89 \mathrm{dph}-63 \mathrm{~mm}$ SL in the occipital and anterior abdominal region (the posterior-most occipital centrum bears small ribs, also see Grande, 2010). They progressively ossify posteriorly to the middle of the abdominal region at $118 \mathrm{dph}-87 \mathrm{~mm}$ SL (Fig. 3, models At9, At10, At11 and At12).

\section{Haemal arches, haemal spines and hypurals.}

Haemal arches are paired elements ventral to the centra located in the caudal region, and bear unpaired and elongated haemal spines. The haemal canal goes in between the arches. Hypurals are the posterior-most haemal spines (Arratia and Schultze, 1992), but are not born by haemal arches since the canal does not reach the tip of the tail. They are therefore directly connected to the centra. The distinction between 
hypurals and haemal spines is made hard in 3D models since it is sometimes impossible to tell whether an elongated element is supported or not by a bifurcating, haemal arch (if the arch is not ossified). To identify hypurals, we used the position of a series of lepidotrichia in the caudal fin that are systematically folded (hence identifiable since caudal lepidotrichia ossify early, see below) at their proximal tip, where they attach to the hypurals (Grande, 2010). The anterior-most ray of this series and the ray anterior to it both branch onto hypural 2 in Grande (2010), and the ray before branches onto hypural 1. To be sure of the identity of hypural 1, we also checked that it was not bifurcating at its tip.

The first haemal arches and spines (connected together), and the first hypurals, are detected in the tail at $31 \mathrm{dph}-39 \mathrm{~mm}$ SL (Fig.2B and model At6). The ossification of hypurals spreads backwards, further than the neural arches, neural spines and epurals (model At12). On the contrary, ossification of haemal arches spreads forwards and reaches the posterior limit of the abdominal region at $89 \mathrm{dph}-63 \mathrm{~mm}$ SL (haemal spines ossification does not reach the anterior limit of the haemal arches, see model At12).

\section{Endoskeleton - the appendicular skeleton}

In actinopterygians, fin rays are bony segmented elements called lepidotrichia. The fin is attached to the body either directly (dorsal, anal and caudal, unpaired fins) or via a girdle (pectoral and pelvic, paired fins). Except for the pelvic fins, all fins have their lepidotrichia born by bony support elements called radials. In the dorsal and anal fins, radials are organized in pterygiophores, each of which is made of a proximal, a middle and a distal radial, of which only the latter bears the rays. Distal radials remain cartilaginous in gars (Grande, 2010) and are the only radials occurring in the caudal fin.

\section{Pectoral girdle.}

The cleithrum and supracleithrum are already mineralized at $13 \mathrm{dph}-21 \mathrm{~mm}$ TL (Fig. 1A) and connect to one another at $22 \mathrm{dph}-30 \mathrm{~mm}$ SL (model At4), although they are separate in our $26 \mathrm{dph}-32 \mathrm{~mm}$ SL specimen (model At5). The postcleithrum is first detected on the left side of the specimen at 37dph $-43 \mathrm{~mm}$ SL (Fig. 2C, and model At7) barely connected with the supracleithrum, and then bilaterally at $52 \mathrm{dph}-46 \mathrm{~mm}$ SL (At8). The cleithrum connects to the postcleithrum on the right side, at $89 \mathrm{dph}-63 \mathrm{~mm}$ SL (At10). There is still no ossified trace of the pectoral fins at 118dph - 87mm SL (see model At12). Alcian blue colorations show that they remain cartilaginous until this advanced stage (data not shown).

\section{Pelvic girdle.}

The basipterygium (the single bone of the pelvic girdle) mineralizes between $37 \mathrm{dph}-43 \mathrm{~mm}$ SL (see model At7) and 52dph-46mm SL (Fig. 3A and model At8).

\section{Caudal, anal and dorsal fins.}

The first dorsal and anal proximal radials ossify at $37 \mathrm{dph}-$ $43 \mathrm{~mm}$ SL (see model At7). We did not detect in our larval series any ossification of the middle and distal radials in any of the fins.

\section{Exoskeleton \\ Fin rays.}

The first caudal lepidotrichia are detected at 19dph $-27 \mathrm{~mm}$ SL (see model At3). The first anal and dorsal lepidotrichia calcify at 26dph $-32 \mathrm{~mm}$ SL (Fig. 2A and model At5). The first pelvic lepidotrichia ossify at $31 \mathrm{dph}-39 \mathrm{~mm}$ SL (Fig. 2B). Rudimentary fin rays, which are unsegmented rays at the edges of the fins, start to ossify in the dorsal fin and in the ventral and dorsal edges of the caudal fin at $31 \mathrm{dph}-39 \mathrm{~mm}$ SL (see model At6), and in the anal fin at $37 \mathrm{dph}-43 \mathrm{~mm}$ SL (Fig. 2C and At7). Finally, a basal fulcrum, which is the first small ray at the edge of a fin (before the rudimentary fin rays), was detected at the dorsal and ventral edges of the caudal fin at 74dph - 61mm SL (see model At9). Pectoral lepidotrichia are still not ossified at $118 \mathrm{dph}-87 \mathrm{~mm}$ SL (At12).

\section{Fangs.}

Because we set the resolution of the $\mu \mathrm{CT}$ at $18 \mu \mathrm{m}$ voxel size, only the biggest teeth (the fangs, sensu Grande, 2010) are visible on our 3D reconstructions. The first fangs are detected on the premaxilla at $19 \mathrm{dph}-27 \mathrm{~mm}$ SL (see model At3). More fangs are visible on the dermopalatine and the dentary at $26 \mathrm{dph}-32 \mathrm{~mm}$ SL (see model At5) and additional fangs appear on the vomer and the lacrimomaxillae at 31dph - 39mm SL (see model At6).

\section{Scales.}

Several rows of ganoid scales are first detected on the flanks between the dorsal-anal fins and the caudal fin area at 118dph $-87 \mathrm{~mm}$ SL (Fig. 3E and model At12).

\section{Entoglossals.}

Two parallel, antero-posteriorly oriented rows of bony plates are present on the top of the tongue and detected at $89 \mathrm{dph}-$ $63 \mathrm{~mm}$ SL (see model At10). They are referred to as entoglossals and form the basihyal tooth plate, attached to the hyoid complex in adults (Grande, 2010).

\section{DISCUSSION}

In this study we describe a large sequence of ossification events throughout larval development in Atractosteus tristoechus, thanks to a high density of stages (12 stages). We show that the first bones mineralize around the stage 13dph $-21 \mathrm{~mm}$ TL (see model At1) and that at 118dph - 87mm SL (see model At12) most of the adult bones are ossified.

\section{Missing steps.}

Still, some structures are lacking in our reconstructions, or not clearly visible. In the skull, this is the case for: the coronoids that are supposed to cover the mandible and bear teeth (Grande, 2010); the pterosphenoid and orbitosphenoid in the braincase region; a second dermopalatine, smaller and posterior to the first one (although not present in all adult 


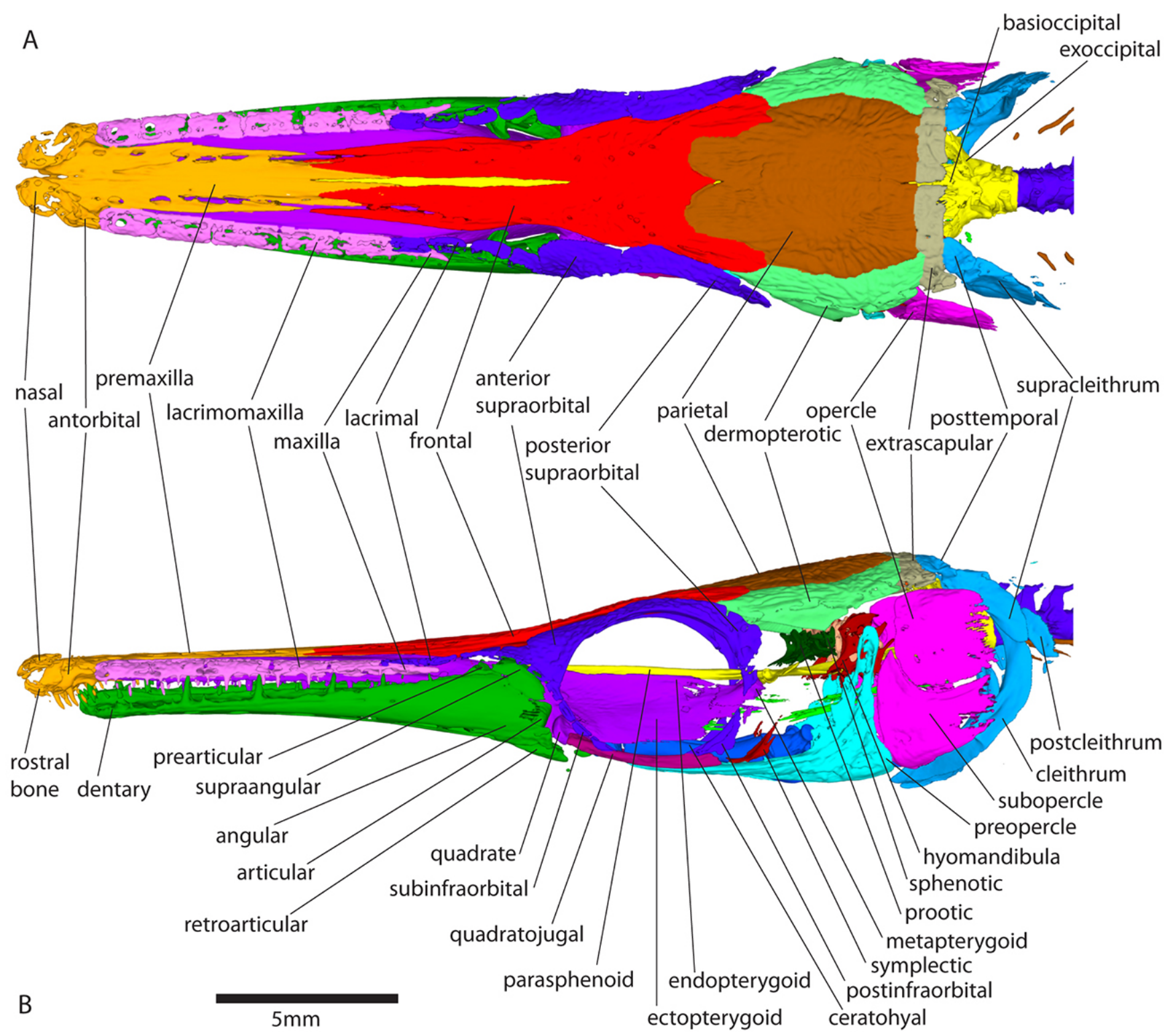

Figure 4. Dorsal (A) and left lateral (B) view of the cranial skeleton described in the oldest larval stage (At12 118dph - 87mm SL). 
specimens in Grande, 2010); the large series of small dermal suborbital bones covering the cheeks posterior to the orbit; and the dermohyal bone, an ornamented and superficial dermal bone in the temporal area, overlaying the dorsal limits of the preopercle and opercle. Some bony elements of the gill arches are also lacking at $118 \mathrm{dph}-87 \mathrm{~mm}$ SL (see model At12), probably still cartilaginous. All the elements of the dorsal arches (i.e. infrapharyngobranchials and epibranchials) but the upper pharyngeal tooth plate are lacking, although it is difficult to assess whether the third pair of infrapharyngobranchials is really missing since it is supposed to be attached to the tooth plate, and our limited resolution does not allow this observation. In the ventral arches, a small spot of the second median and unpaired basibranchial element is supposed to ossify (Grande, 2010) but we do not detect it in our reconstructions. In the vertebral axis, some elements are lacking in the caudal region such as the very last vertebral centra and arches which are not completely ossified. In the fins, not all the rays are ossified, especially the rudimentary rays that constitute the edges of the fins, or the fringing fulcra, which are small unsegmented bony rays supposed to attach to the long lepidotrichia on the edge of a fin (Arratia, 2009). The middle radial elements of the dorsal and anal fins, that ossify in A. spatula (Grande, 2010), did not ossify in our specimens. Notably, the pectoral fins remain in a complete cartilaginous state (both the rays and the support elements; data not shown), while the pectoral girdle ossifies early in the development. The first pectoral fin rays are supposed to ossify between $52 \mathrm{~mm} \mathrm{SL}$ and $61 \mathrm{~mm}$ SL in A. spatula, and they are already present in the smallest specimen of A. tristoechus and ossify early in L. osseus (Grande, 2010). This retention of a cartilaginous, larval fin late in the development of A. tristoechus could therefore be a unique, derived feature of this species within Lepisosteiformes. Finally, the ganoid scales that cover the body of all adult species of gars are only mineralized in the caudal region of our oldest specimen.

\section{Technical limitations.}

Our developmental series are based on X-ray microtomography only, which does not allow capturing the finest scale anatomical details, because of the limited resolution of our protocol (voxel size: $18 \mu \mathrm{m}$ ) and a pre-set threshold for surface complexity (the number of vertices of each surface). For instance, small teeth are supposed to be abundant on many bones of the oral cavity early in the development (Grande, 2010), but we were able to detect only the largest fangs and could not reconstruct a surface showing the small-tooth plates on the vomer, the parasphenoid, the ectopterygoid, the endopterygoid, the prearticular as well as the lower pharyngeal tooth plate on the fifth ceratobranchial.

\section{Asymmetry.}

According to Grande (2010) some paired elements may display a left-right asymmetry in gars. Here we find a similar result with the lacrimomaxillae and lacrimal bones of some of our developmental stages of A. tristoechus. In the lacrimomaxillary series, a difference of one element between the left and right sides is detected at 19dph $-27 \mathrm{~mm}$ SL (At3); 74dph - 61mm SL (At9) and 118dph - 87mm SL (At12), see Fig. 4. A difference of two elements in the lacrimomaxillary series is detected at $89 \mathrm{dph}-63 \mathrm{~mm}$ SL (see model At10). A one-difference asymmetry is also detected in lacrimals at 26dph - 32mm SL (At5); 31dph - 39mm SL (At6 ); 37dph 43mm SL (At7); 74dph - 61 mm SL (At9) and 89dph - 62mm SL (At10). No asymmetry is observed for the extrascapulars in our specimen, unlike Grande (2010). We often observed asynchronous ossifications or connections between left and right elements of paired structures. Such asymmetries were detected for the ossification of the supraangular, lacrimals, dermosphenotic, otoliths and postcleithrum; as well as for the connections between the intermediate extrascapular and the parietal, the medial extrascapular and the posttemporal, the lateral extrascapular and the dermopterotic, the posterior supraorbital and the dermopterotic, and the postinfraorbitals and the dermosphenotic.

\section{Inter-individual variability.}

Intra-population variability may arise in left-right asymmetry but also in the tempos of ossification. Here, asymmetry was not constant for all specimens, which may suggest that within a sample of specimens of the same age, some will display asymmetry and others not. Second, some reductions in numbers of repeated elements from one stage to the next one also imply intra-population variability. For example, six left lacrimomaxillae are detected at 74dph $-61 \mathrm{~mm}$ (At9) SL while only five are detected at 89dph $-63 \mathrm{~mm}$ SL (At10); and eight left lacrimals are detected at $89 \mathrm{dph}-63 \mathrm{~mm} \mathrm{SL}$ (At10) while only seven are detected at 104dph $-70 \mathrm{~mm} \mathrm{SL}$ (At11). Thus, different individuals may have different ossification rhythms, but may also have a different final number of elements of each type, consistently with Grande (2010) who shows that all adult individuals do not share the same number of lacrimomaxillae, lacrimals, suborbitals, extrascapulars and dermopalatines. One may notice that the number of lacrimomaxillae is reduced in the $118 \mathrm{dph}-87 \mathrm{~mm}$ SL specimen (see model At12: five and six lacrimomaxillae, Fig. 4, versus seven on both sides at 104dph - 70mm SL, see model At11). It might be due to intra-population variability, but such a big reduction can also be due to a fusion of lacrimomaxillae as proposed by Grande (2010). Lastly, it is also likely that for a same age, all specimens do not share the same standard length. With regard to these arguments, scanning several specimens per stage could be useful to cover and assess inter-individual variability.

\section{Directional ossification.}

Overall, ossification seems directed from anterior to posterior of the body, but this pattern is also seen at smaller scales e.g. within the skull. First, several cranial bones are already ossified at $13 \mathrm{dph}-21 \mathrm{~mm}$ TL (Fig. 1A and model At1) while the first post-cranial elements truly independent from the skull (i.e. not the pectoral girdles) are the caudal 
lepidotrichia, detected at $19 \mathrm{dph}-27 \mathrm{~mm}$ SL (At3) and the first non-occipital vertebral centra ossify at $22 \mathrm{dph}-30 \mathrm{~mm}$ SL (At4). Second, the same pattern holds for the appendicular development. Pectoral girdles start to develop before $13 \mathrm{dph}$ $-21 \mathrm{~mm}$ TL (Fig. 1A and model At1) and are well ossified as early as 52dph - 46mm SL (Fig. 3A and model At8), contrasting with posterior fins that ossify later. Third, the skull ossifies backwards as well: the earlier ossifying bones are the anterior-most. The snout and jaw elements are already present at $13 \mathrm{dph}-21 \mathrm{~mm}$ TL (Fig. 1A and model At1), in particular the premaxilla, the maxilla, the dermopalatine, the ectopterygoid and the dentary. All the more posterior elements come later in the development: otic bones (prootic, sphenotic); gill arches; hyomandibular-symplectic apparatus; and the posterior ornamented dermatocranial bones (parietal, dermopterotic, extrascapulars, opercle, subopercle, posttemporal). Finally, vertebral ossification is also generally directed from anterior to posterior, with the specificity that ossifications of all the different types of elements are delayed in time. Vertebral centra (both dorsal and ventral origins of ossification) mineralize first, then neural arches and neural spines, while ribs and supraneurals come at last. Exceptions to this general anterior-posterior pattern of ossification include the scales that start ossifying on the flanks of the caudal region, the haemal arches whose calcification spreads forward, and the fin rays that mineralize first in the caudal fin, then in the dorsal, anal and pelvic fins, and that are still missing at $118 \mathrm{dph}$ $-87 \mathrm{~mm}$ SL (At12) in the pectoral fins.

\section{Specificities in Atractosteus}

Some features of Atractosteus tristoechus are shared with A. spatula but are different from the genus Lepisosteus. In adult $A$. spatula and $A$. tristoechus the dermosphenotic bone is not part of the circumorbital ring (which is therefore made of supraorbitals, postinfraorbitals, subinfraorbitals and a lacrimal) while it is in Lepisosteus and A. tropicus, and two extinct species: $\uparrow A$. falipoui and $\dagger$ A. simplex, as well as in many other actinopterygians. Grande (2010) showed that the dermosphenotic reaches the orbital margin in young $A$. spatula and is then moved backwards by the growth of the posterior supraorbital somewhere between 242mm SL and 529mm SL. Consistently, in A. tristoechus we detect the dermosphenotic as surrounding the orbit until 118dph $-87 \mathrm{~mm}$ SL (Fig. 4 and At12), suggesting that any displacement occurs later on. Another point is that we do not find in A. tristoechus any structure resembling the mobile posterior maxillae fragments of Lepisosteus, a result similar to A. spatula in which there is only a fibrous element covering the supraangular in adults but that does not display any clue for homology with a maxilla (Grande, 2010). We could not detect such a fibrous element in A. tristoechus as it is not mineralized.

\section{CONCLUSION}

Our results provide a new point of view for a detailed description of the development of the skeleton in Atractosteus tristoechus. Ossification times of many structures could be assessed, thanks to a high density in developmental stages. Still, some questions remain open, such as structures that do not ossify within our developmental range, or the degree of intra-population variability. The study of more specimens and the use of alternative skeletal staining techniques (Alizarine red and Alcian blue) will allow a more detailed and more accurate description of these developmental events.

\section{ACKNOWLEDGEMENTS}

The authors are grateful to Renaud Lebrun and Lionel Hautier for help with the $\mu$ CT-scan. We also thank Sébastien Enault and Philippe Janvier for discussions on anatomical terminology. We thank Nalani Schnell and Murilo Carvalho for fruitfull comments. This article is ISEM contribution \# ISEM 2017-095.

\section{BIBLIOGRAPHY}

Arratia, G., 2009. Identifying patterns of diversity of the actinopterygian fulcra. Acta Zoologica. 90, 220-235. https: //doi.org/10.1111/j.1463-6395.2008.00375.x

Arratia, G., Schultze, H.-P., 1991. Palatoquadrate and Its Ossifications: Development and Homology Within Osteichthyans. Journal of Morphology. 208, 1-81. https://doi.org/10.1002/j mor. 1052080102

Arratia, G., Schultze, H.-P., 1992. Reevaluation of the caudal skeleton of certain actinopterygian fishes: III. Salmonidae. Homologization of caudal skeletal structures. Journal of Morphology. 214, 187-249. https://doi.org/10.1002/jmor. 1052140209

Betancur-R, R., Broughton, R.E., Wiley, E.O., Carpenter, K., López, J.A., Li, C., Holcroft, N.I., Arcila, D., Sanciangco, M., Ii, J.C.C., Zhang, F., Campbell, M.A., Ballesteros, J.A., Roavaron, A., Willis, S., Borden, W.C., Hough, D.J., Lu, G., 2013. The Tree of Life and a New Classification of Bony Fishes. PLOS Currents Tree of Life. 732988, 1-45. https://doi.org/ 10.1371/currents.tol.53ba26640df0ccaee75bb165c8c26288

Boughner, J.C., Buchtová, M., Fu, K., Diewert, V., Hallgrímsson, B., Richman, J.M., 2007. Embryonic development of Python sebae - I: Staging criteria and macroscopic skeletal morphogenesis of the head and limbs. Zoology. 110, 212-230. https://doi.org/10.1016/j.zool.2007.01.005

Britz, R., Johnson, G.D., 2010. Occipito-vertebral fusion in actinopterygians: conjecture, myth and reality. Part 1: Nonteleosts. In: Mesozoic Fishes 4-Homology and Phylogeny. J. S. Nelson, H.-P. Schultze, and M. V. H. Wilson (Eds.). Verlag Dr. Freidrich Pfeil, München. pp. 77-93.

Broughton, R.E., Betancur-R., R., Li, C., Arratia, G., Ortí, G., 2013. Multi-locus phylogenetic analysis reveals the pattern and tempo of bony fish evolution, PLoS Currents Tree of Life. 
Cignoni, P., Cignoni, P., Callieri, M., Callieri, M., Corsini, M., Corsini, M., Dellepiane, M., Dellepiane, M., Ganovelli, F., Ganovelli, F., Ranzuglia, G., Ranzuglia, G., 2008. MeshLab: an Open-Source Mesh Processing Tool. Sixth Eurographics Italian Chapter Conference. 129-136.

Dean, M.N., Mull, C.G., Gorb, S.N., Summers, A.P., 2009. Ontogeny of the tessellated skeleton: Insight from the skeletal growth of the round stingray Urobatis halleri. Journal of Anatomy. 215, 227-239. https://doi.org/10.1111/j.14697580.2009.01116.x

Dufeau, D.L., Witmer, L.M., 2015. Ontogeny of the MiddleEar Air-Sinus System in Alligator mississippiensis (Archosauria: Crocodylia). PLoS ONE. 10, 1-25. https://doi.org/10.1371/j ournal.pone.0137060

Enault S., Adnet S., Debiais-Thibaud M., 2016. Skeletogenesis during the late embryonic development of the catshark Scyliorhinus canicula (Chondrichthyes; Neoselachii). MorphoMuseuM 1 (4)-e2. https://doi.org/10.18563/m3.1.4.e2

Friedman, M., 2015. The early evolution of ray-finned fishes. Palaeontology. 58, 213-228. https://doi.org/10.1111/pala.12 150

Gardiner, B.G., Littlewood, D.T.G., Maisey, J.G., 1996. Interrelationships of basal neopterygians. In: Stiassny, M.L.J., Parenti, L.R., Johnson, G.D. (Eds.), Interrelationships of Fishes. Academic Press, San Diego, California, pp. 117-146. https://doi.org/10.1016/B978-012670950-6/50007-2

Gardiner, B.G., Schaeffer, B., 1989. Interrelationships of lower actinopterygian fishes. Zoological Journal of the Linnean Society. 1989, 135-187. https://doi.org/10.1111/j.10963642.1989.tb00550.x

Gardiner, B.G., Schaeffer, B., Masserie, J.A., 2005. A review of the lower actinopterygian phylogeny. Zoological Journal of the Linnean Society. 144, 511-525. https://doi.org/10.11 11/j.1096-3642.2005.00181.x

Gegenbauer, C., 1887. Ueber die Occipitalregion und die ihr benachbarten Wirbel der Fische. In: Festschrift Albert von Kölliker Zur Feier Seines Siebenzigsten Geburtstages Gewidmet von Seinen Schülern. W. Engelmann, Leipzig.

Grande, L., 2010. An empirical synthetic pattern study of gars (Lepisosteiformes) and closely related species, based mostly on skeletal anatomy. The resurrection of Holostei., American Society of Ichthyologists and Herpetologists Special Publication 6:i-x, 1-871; supplementary issue of Copeia 10 (2A).

Grande, L., Bemis, W.E., 1991. Osteology and phylogenetic relationships of fossil and recent paddlefishes (Polyodontidae) with comments on the interrelationships of Acipenseriformes. Journal of Vertebrate Paleontology. 11, 1-121. https://doi.org/10.1080/02724634.1991.10011424

Grande, L., Bemis, W.E., 1998. A Comprehensive Phylogenetic Study of Amiid Fishes (Amiidae) Based on Comparative Skeletal Anatomy. an Empirical Search for Inter- connected Patterns of Natural History. Journal of Vertebrate Paleontology. 18, 1-696. https://doi.org/10.1080/02724634.1 998.10011114

Gregory, W.K.K., 1959. Fish skulls - A study of the evolution of natural mechanisms, Transactions of the American Philosophical Society. Eric Lundberg, Laurel, Florida.

Hammarberg, F., 1937. Zur Kenntnis der Ontogenetischen Entwicklung des Schädels von Lepisosteus platystomus. Acta Zoologica. 18, 210-336. https://doi.org/10.1111/j.1463-63 95.1937.tb00680.x

Helfman, G., Collette, B., Facey, D., 2009. The diversity of fishes-biology, evolution, and ecology, 2nd edition. WileyBlackwell, Oxford, UK.

Hilton, E.J., Konstantinidis, P., Schnell, N.K., Dillman, C.B., 2014. Identity of a unique cartilage in the buccal cavity of gars (Neopterygii: Lepisosteiformes: Lepisosteidae). Copeia. 2014, 50-55. https://doi.org/10.1643/CI-12-173

Hilton, E.J., Schnell, N.K., Konstantinidis, P., 2015. When Tradition Meets Technology: Systematic Morphology of Fishes in the Early 21st Century. Copeia. 103, 858-873. https://doi.org/10.1643/CI-14-178

Ho, T.V., Iwata, J., Ho, H.A., Grimes, W.C., Park, S., SanchezLara, P.A., Chai, Y., 2015. Integration of comprehensive 3D microCT and signaling analysis reveals differential regulatory mechanisms of craniofacial bone development. Developmental Biology. 400, 180-190. https://doi.org/10.1016/j.ydbio. 2015.02.010

Hurley, I.A., Mueller, R.L., Dunn, K.A., Schmidt, E.J., Friedman, M., Ho, R.K., Prince, V.E., Yang, Z., Thomas, M.G., Coates, M.I., 2007. A new time-scale for ray-finned fish evolution. Proceedings. Biological sciences / The Royal Society. 274, 489-498. https://doi.org/10.1098/rspb.2006.3749

Huysseune, A., Sire, J.-Y., 1998. Evolution of patterns and processes in teeth and tooth-related tissues in non-mammalian vertebrates. European journal of oral sciences. 106, 437-481. https://doi.org/10.1111/j.1600-0722.1998.tb02211.x

Jessen, H., 1972. Schultergürtel und Pectoralflosse bei Actinopterygiern. Fossil Strata. 1, 1-101.

Jollie, M., 1984. Development of Cranial and Pectoral Girdle Bones of Lepisosteus with a Note on Scales. Copeia. 2, 476-502. https://doi.org/10.2307/1445204

Kammerer, C.F.F., Grande, L., Westneat, M.W.W., 2006. Comparative and Developmental Functional Morphology of the Jaws of Living and Fossil Gars (Actinopterygii: Lepisosteidae). Journal of morphology. 267, 1017-31. https: //doi.org/10.1002/jmor.10293

Konstantinidis, P., Warth, P., Naumann, B., Metscher, B., Hilton, E.J., Olsson, L., 2015. The Developmental Pattern of the Musculature Associated with the Mandibular and Hyoid Arches in the Longnose Gar, Lepisosteus osseus (Actinopterygii, Ginglymodi, Lepisosteiformes). Copeia. 103, 920-932. https://doi.org/10.1643/OT-14-195 
Kryzanovsky, S., 1927. Die Entwicklung der paarigen Flossen bei Acipenser, Amia und Lepidosteus. Acta Zoologica. 8, 278-352.

Lauder, G. V., 1980. Evolution of the feeding mechanism in primitive actionopterygian fishes: A functional anatomical analysis of Polypterus, Lepisosteus, and Amia. Journal of Morphology. 163, 283-317. https://doi.org/10.1002/jmor. 1051630305

Lebrun, R., 2014. ISE-MeshTools, a 3D interactive fossil reconstruction freeware. In: 12th Annual Meeting of EAVP, Torino, Italy.

Lecointre, G., Philippe, H., Van Le, H.L., Le Guyader, H., 1994. How many nucleotides are required to resolve a phylogenetic problem? The use of a new statistical method applicable to available sequences. Molecular Phylogenetics and Evolution. https://doi.org/10.1006/mpev.1994.1037

Long, J.M., Snow, R.A., 2016. Ontogenetic development of otoliths in alligator gar. Transactions of the American Fisheries Society. 145, 537-544. https://doi.org/10.1080/ 00028487.2015.1135189

Long, W.L., Ballard, W.W., 2001. Normal embryonic stages of the longnose gar, Lepisosteus osseus. BMC developmental biology. 1, 6. https://doi.org/10.1186/1471-213X-1-6

López-Arbarello, A., 2012. Phylogenetic Interrelationships of Gynglymodian Fishes (Actinopterygii: Neopterygii). PLoS ONE. 7, 1-44. https://doi.org/10.1371/journal.pone.0039370

Luther, A., 1913. Ueber die vom N. trigeminus versorgte Muskulatur der Ganoiden und Dipneusten. Helsingfors Acta Societas Scientiarum Fennica. 41, 1-72.

Maxwell, E.E., Wilson, L.A.B., 2013. Regionalization of the axial skeleton in the "ambush predator" guild - are there developmental rules underlying body shape evolution in rayfinned fishes? BMC Evolutionary Biology. 13, 265. https: //doi.org/10.1186/1471-2148-13-265

Mayhew, R.L., 1924. The skull of Lepidosteus platostomus. Journal of Morphology. 38, 315-346. https://doi.org/10.1002 /jmor.1050380303

Metscher, B.D., 2009. MicroCT for developmental biology: A versatile tool for high-contrast 3D imaging at histological resolutions. Developmental Dynamics. 238, 632-640. https: //doi.org/10.1002/dvdy.21857

Near, T.J., Eytan, R.I., Dornburg, A., Kuhn, K.L., Moore, J.A., Davis, M.P., Wainwright, P.C., Friedman, M., Smith, W.L., 2012. Resolution of ray-finned fish phylogeny and timing of diversification. Proceedings of the National Academy of Sciences. 109, 13698-13703. https://doi.org/10.1073/pnas.1 206625109

Nelson, J.S., Grande, T.C., M. V. H. W, 2016. Order LEPISOSTEIFORMES - gars. In: Fishes of the World. John Wiley \& Sons, New York.
Normark, B.B., McCune, a R., Harrison, R.G., 1991. Phylogenetic relationships of neopterygian fishes, inferred from mitochondrial DNA sequences. Molecular biology and evolution. 8, 819-834.

Palci, A., Lee, M.S.Y., Hutchinson, M.N., 2016. Patterns of postnatal ontogeny of the skull and lower jaw of snakes as revealed by micro-CT scan data and three-dimensional geometric morphometrics. Journal of Anatomy. https://doi. org/10.1111/joa.12509

Perry, S.F., Wilson, R.J. a, Straus, C., Harris, M.B., Remmers, J.E., 2001. Which came first, the lung or the breath? Comparative Biochemistry and Physiology - A Molecular and Integrative Physiology. 129, 37-47. https://doi.org/10.1016/S10956433(01)00304-X

Rice, R., Kallonen, A., Cebra-Thomas, J., Gilbert, S.F., 2016. Development of the turtle plastron, the order-defining skeletal structure. Proceedings of the National Academy of Sciences of the United States of America. 113, 5317-5322. https: //doi.org/10.1073/pnas.1600958113

Rücklin, M., Donoghue, P.C.J., Cunningham, J.A., Marone, F., Stampanoni, M., 2014. Developmental Paleobiology of the Vertebrate Skeleton. Journal of Paleontology. 88, 676-683. https://doi.org/10.1666/13-107

Schindelin, J., Arganda-Carreras, I., Frise, E., Kaynig, V., Longair, M., Pietzsch, T., Preibisch, S., Rueden, C., Saalfeld, S., Schmid, B., Tinevez, J.-Y., White, D.J., Hartenstein, V., Eliceiri, K., Tomancak, P., Cardona, A., 2012. Fiji: an opensource platform for biological-image analysis. Nature Methods. 9, 676-682. https://doi.org/10.1038/nmeth.2019

Schmalhausen, J.J., 1913. Zur Morphologie der unpaaren Flossen. II. Bau und Phylogenese der unpaaren Flossen und insbesonders der Schwanzflosse der Fische. Zeitschrift für wissenschaftliche Zoologie. 104, 1-80.

Schreiner, K.E., 1902. Einige Ergebnisse über den Bau und der Occipitalregion von Amia und Lepidosteus. Zetischriften. wiss. Zool. 72, 467-524.

Schultze, H.-P., Cloutier, R., 1991. Computed Tomography and Magnetic Resonance Imaging studies of Latimeria chalumnae. Environmental Biology of Fishes. 32, 159-181. https://doi.org/10.1007/BF00007451

Sewertzoff, A.N., 1895. Die Entwicklung der Occipitalregion der niederen Vertebraten im Zusammenhang mit der Frage nach der Metamerie des Kopfes. Bulletin de la société impériale des naturalistes de Moscou. 9, 186-284.

Shen, L., Ai, H., Liang, Y., Ren, X., Anthony, C.B., Goodlett, C.R., Ward, R., Zhou, F.C., 2013. Effect of prenatal alcohol exposure on bony craniofacial development: a mouse MicroCT study. Alcohol (Fayetteville, N.Y.). 47, 405-15. https://doi.org/10.1016/j.alcohol.2013.04.005

Sire, J.-Y., 1989. Scales in Young Polypterus senegalus Are Elasmoid: New Phylogenetic Implications. The American 
Journal of Anatomy. 186, 315-323. https://doi.org/10.1002/a ja. 1001860308

Sire, J.-Y., 1990. From ganoid to elasmoid scales in the actinopterygian fishes. Netherlands journal of zoology. 40, 75-92. https://doi.org/10.1163/156854289X00192

Sire, J.-Y., Donoghue, P.C.J., Vickaryous, M.K., 2009. Origin and evolution of the integumentary skeleton in non-tetrapod vertebrates. Journal of Anatomy. 214, 409-440. https://doi. org/10.1111/j.1469-7580.2009.01046.x

Sire, J.-Y., Géraudie, J., Meunier, F.J., Zylberberg, L., 1987. On the Origin of Ganoine: Histological and Ultrastructural Data on the Experimental Regeneration of the Scales of Calamoichthys calabaricus (Osteichthyes, Brachyopterygii, Polypteridae). The American Journal of Anatomy. 180, 391-402. https://doi.org/10.1002/aja.1001800409

Slater, B.J., Liu, K.J., Kwan, M.D., Quarto, N., Longaker, M.T., 2009. Cranial osteogenesis and suture morphology in Xenopus laevis: A unique model system for studying craniofacial development. PLoS ONE. 4. https://doi.org/10. 1371/journal.pone.0003914

Veit, O., 1907. Über einige Besonderheiten am Primordialcranium von Lepidosteus osseus. Anatomische Hefte. 99, 155-204.

Vickaryous, M.K., Sire, J.Y., 2009. The integumentary skeleton of tetrapods: Origin, evolution, and development. Journal of Anatomy. 214, 441-464. https://doi.org/10.1111/j.14697580.2008.01043.x

Wiley, E.O., 1976. The phylogeny and biogeography of fossil and recent gars (Actinopterygii: Lepisosteidae). University of Kansas Museum of Natural History Miscellaneous Publications. 64, 1-111. 